\title{
Hacia una tipología de los finales poéticos en la lírica de Olga Orozco
}

Víctor Gustavo ZonANA Universidad Nacional de Cuyo - CONICET

Resumen: En la poesía de Olga Orozco pervive un eco de su voz, esencialmente ritual, sustentado en la línea versicular y la andadura rítmica que combina heptasílabos y endecasílabos. Junto con la estructura métrica, existen otros marcadores de estilo que coadyuvan en su percepción, por ejemplo, los finales poéticos. Se trata de un rasgo relacionado con su modo de comprender la poesía. Para abordar su análisis se adopta el siguiente plan: primero, un desarrollo de la categoría "final de poema"; segundo, el examen de la relación de los finales poéticos con su comprensión de la poesía y con sus reflexiones en torno al proceso de escritura; tercero, el reconocimiento de los distintos tipos de final poético presentes en sus libros; por último, una ponderación sobre los alcances del examen en relación con la constitución de la voz de Olga Orozco.

Palabras clave: Olga Orozco, lírica, final poético, voz, estilo

\section{Towards a typology of the poetic ending in Olga Orozco's lyric}

Resumen: In Olga Orozco's poetry an echo of her voice, essentially ritual, survives. It is based in the long biblical line and the rhythmic path that combines heptasyllabes and endecasyllabes. Besides with the metric structure, there are other style markers that contribute to its perception, for instance, how her poems end. It is a main feature, related to her way of understanding poetry. The study adopt the following plan: first, a synthetic developement of poem ending category; second, the examination of the relationship of poetic endings with Orozco's understanding of poetry; third, the recognition of the different dominant types of poetic ending present in her poetics books; finally, an evaluation of the importance of this feature in the constitution of Olga Orozco's voice.

Palabras clave: Olga Orozco, poetry, poetic ending, voice, style 


\section{Introducción}

En la escritura de Olga Orozco pervive, como señala agudamente Jorge Monteleone, un eco de su voz (2020: 17-21). El conjunto de su obra (lírica, narrativa, teórica y crítica, periodística) exhibe la figura de «la voz de Olga» con modulaciones diversas (Monteleone, 2020: 27). La modulación lírica de la voz es esencialmente ritual (Monteleone, 2020: 18). La puesta en página del poema con sus versículos incontenibles y la andadura rítmica que se imprime en ellos mediante la combinatoria de heptasílabos y endecasílabos (Zonana, 2010), inducen una lectura que permite percibir ese singular eco oral. Cabría preguntarse si, junto con la estructura métrica y prosódica, no existen otros marcadores de estilo que coadyuven en su percepción.

Un repaso sintético de la bibliografía revela que este es un aspecto menos transitado en el estudio de su obra, al menos recientemente ${ }^{1}$. Para abordajes parciales del estilo orozquiano o de las estrategias compositivas dominantes en su poesía y su narrativa, es necesario remitirse a estudios anteriores ${ }^{2}$. Como un modo de contribuir al reconocimiento de los factores que favorecen la percepción de «la voz de Olga Orozco» y de su índole ritual en su lírica, el objetivo de este trabajo consiste en realizar una aproximación holística a un rasgo de estilo poco considerado: los finales poéticos. Se trata de un rasgo de singular importancia en la constitución del talante religioso y oracular que suele asignarse a su lírica de largo aliento. Un rasgo que, además, se relaciona estrechamente con su modo de comprender la poesía y que puede

\footnotetext{
1 Como ejemplos ilustrativos pueden enumerarse algunos hitos: el volumen en homenaje a la recepción del premio Juan Rulfo editado por José Brú (1998), la compilación internacional de Inmaculada Lergo Martín (2009) con ocasión de los diez años de su fallecimiento, el estudio comprensivo de María Elena Legaz (2010) y los trabajos recogidos y coordinados por Graciela Salto, Dora Battiston y Sonia Bertón en dos valiosos tomos (2020). En estas obras se pueden observar ciertas preferencias hacia su poética, su encuadre regional, nacional e internacional, ciertos libros como Las muertes, Museo salvaje y la representación del cuerpo, los libros de relatos, la intertextualidad, las formas de representación del yo y sus correlatos en cada libro, ciertos ejes temáticos persistentes como el silencio, la memoria o el tiempo.

2 Pueden mencionarse, por ejemplo, los de Liscano (1975) sobre el versículo, el tono oracular y el símbolo, Luzzani Bystrowicz (1981) sobre las estructuras oximorónicas como base de su discurso orozquiano, Tacconi (1981) sobre el uso de los símbolos referidos a la muerte, el paraíso y el tiempo, Stella Maris Colombo sobre los conjuntos metafóricos y su fundamento cosmovisionario (1983), Piña (1984) sobre la imagen, los símbolos y el tono oracular, Cobo Borda (1984) sobre la línea versicular y el uso de imágenes, López de Espinoza (1987) sobre el símbolo de la máscara y su relación con la problemática de la identidad, Running (1987) sobre la imagen como fundamento de la enunciación poética, Pellarolo (1989) sobre el símbolo de la estatua de sal y su relación con la poética o Flores (1996) sobre marcadores como el símbolo, la metáfora, la intertextualidad y la amplificación.
} 
entenderse si se recuperan sus reflexiones sobre la manera de emprender el proceso de escritura.

Para abordar su análisis se adopta el siguiente plan de trabajo: en primer lugar un desarrollo sintético de la categoría final de poema a partir de los aportes de Barbara Herrnstein-Smith (1968), Giorgio Agamben (2016) y Nigel Fabb (2016) principalmente; en segundo, el examen de la relación de los finales poéticos con la comprensión que la autora tiene de la poesía y con sus reflexiones en torno al modo en que encara el proceso de escritura; en tercero, el reconocimiento de los distintos tipos dominantes de final poético presentes en sus libros desde Desde lejos (1946) hasta Últimos poemas (2009); por último, una ponderación acerca de los alcances del examen en relación con la comprensión de la constitución de la voz de Olga Orozco.

\section{El final del poema como problema teórico}

Como objeto de estudio teórico, el final del poema puede considerarse al menos desde una triple perspectiva: poética en cuanto a su necesidad, sus modos de manifestación y su finalidad; discursiva en cuanto a los medios tipográficos, lingüísticos y textuales que lo marcan; cognitiva, en cuanto a los procesos que intervienen en su procesamiento y los efectos de lectura que genera.

Desde el punto de vista poético, el final es la última estructura formal perceptible en un texto lírico (Agamben, 2016). Se trata de un constituyente decisivo para la captación del poema como tal, ya que, como destaca Pierre Oullet, éste solo existe en su límite $(2017,14)$. Su manifestación ha sido considerada como un momento de crisis: la (re)caída en el silencio inicial del cual nace el poema (Agamben, 2016; Heller-Roazen, 2003: 80).

Desde una perspectiva lingüístico-discursiva, el final del poema necesita ser marcado (Tamine-Gardes, 1985: 34). A través de la tipografía, mediante la ocupación de la página y el blanco y, en el caso de su enunciación en voz alta, mediante la entonación descendente y el silencio posterior. Ciertas combinaciones estróficas fijas vinculadas a tradiciones literarias, como el soneto o la sextina, subrayan el arribo del final mediante recursos formales. Por ejemplo, el dístico de los sonetos de Shakespeare, con un cambio en el esque- 
ma de la de rima pone de relieve el final, o la sextina con su remate de tres versos que emplea las seis palabras del resto del poema en posición de final de verso. En las cantigas medievales el acceso al final poemático se podía enunciar de manera explícita a través de la finida. Incluso, el marcado formal del final podía implicar un cambio de lengua, registro lingüístico y persona enunciadora, como es el caso de las jarchas adosadas a las moaxajas de la poesía arábigo andaluza (Heller-Roazen, 2003: 82).

Los recursos formales pueden ser solidarios con los del contenido en la determinación del final. La base temática del poema se despliega con una economía particular que relaciona contenidos y propósitos, a tipologías discursivas de base como la argumentación, la descripción de cosas, estados o procedimientos, la explicación o el relato (Bahti, 1990: 1046-1948). Las formas que adopta la progresión temática (Combettes, 1977, 1978; Bertucelli Papi, 1996: 152-154), generan expectativas que pueden cumplirse o no. Estas formas implican elecciones relacionadas con aspectos como el título del poema, la selección de las tipologías discursivas de base y su organización, las creencias y mundos movilizados, los intertextos empleados. Todos estos factores pueden promover en el lector la generación de determinadas expectativas (De Beaugrande, Dressler,1997: 211-224).

Tales expectativas se relacionan además con el carácter "abierto" o "cerrado" del final. Se trata de un aspecto que es necesario distinguir del final propiamente dicho (Luján Atienza, 1999: 90-92). Desde una perspectiva semántica y discursiva, si se tienen en cuenta el contenido y las tipologías de base predominantes en el poema, se puede afirmar que un final es cerrado cuando, por ejemplo, la argumentación arriba a una conclusión, el relato alcanza su resolución, la descripción agota la representación de su objeto. Es decir, las expectativas generadas por todos los constituyentes antes mencionados, se cumplen. Por el contrario, cuando estas condiciones no se cumplen, se puede hablar de un final abierto. Asimismo, cierto tipo de enunciados, como las interrogaciones, pueden dar lugar a un final de esta última índole.

El carácter abierto o cerrado del final del poema y su sentido, dependen de la cosmovisión del escritor y de su concepción de la poesía (Hartman, 1975: 349). Barbara Herrnstein Smith observa en la poesía contemporánea, por ejemplo, una tendencia al debilitamiento del sentido del cierre. Según su opinión, este fenómeno se desprende de una voluntad anti-teleológica y 
de una filosofía de la sospecha en torno a los poderes develatorios del arte (1968: 238-240). También la sospecha sobre toda interpretación globalizante de la existencia determina el tono fragmentario, coloquial y suspensivo de buena parte de la poesía contemporánea. El poema surge entonces como seccionamiento azaroso de un fragmento discursivo y busca destacar su condición de objeto inacabado.

Desde una perspectiva cognitiva, el final del poema constituye un momento fundamental del proceso lector, que puede implicar, de acuerdo con las características de cada poema en particular, un mayor esfuerzo de procesamiento (Herrnstein Smith, 1968; Fabb, 2016). Al acceder al final, el lector reconoce retrospectivamente la forma del poema y evalúa si sus expectativas se han cumplido. El evento terminal, sin embargo, no constituye un punto final. Por el contrario, es una instancia de estabilidad del proceso poético-inferencial. Representa, según Herrnstein Smith, «el momento en que el lector está capacitado para revivir la experiencia del poema ya no como sucesión de eventos, sino como un diseño integral». (1968: 36, la traducción es mía).

\section{El final del poema en la reflexión de Olga Orozco}

Anteriormente se ha señalado que el sentido del final y su condición abierta o cerrada guardan una estrecha relación con el modo en que cada autor concibe la poesía. Los tipos de finales predominantes en la poesía de Olga Orozco se fundamentan en una concepción trascendente de la vida y en la comprensión de la poesía como un medio de acceder a esa dimensión que aparece velada a una captación material o puramente racional de la realidad. Desde este horizonte cosmovisionario, la poesía aparece asociada a la magia y la plegaria. Asimismo, la palabra poética asume una condición interrogativa como un medio de apertura del mundo.

La escritora ha subrayado las semejanzas y diferencias entre poesía, magia y plegaria:

Creo que hay tres maneras de luchar contra la realidad opresiva: la poesía, la plegaria y la magia. La magia es uno de los modos, porque al romper la relación entre causa y efecto te libera de algunas prisiones. Claro que produce una sensación de omnipotencia que es, en verdad, ilusoria. [...] 
la magia convoca poderes hacia abajo. La poesía y la plegaria, en cambio, obligan a una profundización o a una elevación del espíritu para alcanzarlos. La dirección del camino es otra. (Sifrin, 1994: 6)

La plegaria es elevación, pero también es apertura vinculada a la esperanza. En una entrevista con Hugo Beccacece, Olga Orozco explica este sentido de su analogía mediante una combinación singular de distintos pasajes del Nuevo Testamento: el cierre de distintas parábolas en, por ejemplo, Mateo 25, 29, Marcos 4, 25 y Lucas 8, 18, la Epístola a los Romanos 4,18 y el capítulo 6 del Apocalipsis:

Creo que la poesía es una plegaria contra toda esperanza, pero también contra toda desesperanza. Se aguarda la respuesta de Dios aunque no llegue. En la medida en que uno se interna en ese camino de interrogantes y de misterio, la propia obra se hace misteriosa. Ese es para mí el sentido del Evangelio cuando dice: 'Se dará al que tiene'. Si no tienes el misterio no puede ocuparte de él. Todos nosotros somos el misterio. Cada uno de nosotros es su propio enigma. Eso es lo que más me asusta. Llevo mi propia esfinge conmigo. Pero mi respuesta es secreta. Sé que en algún momento me será dado levantar los sellos, pero no de este lado del espejo, aunque no deje nunca de intentarlo. (Beccacece, 1991)

En tanto plegaria, la poesía se dirige a Dios en la inquisición acerca del sentido final del propio sujeto y de la realidad. Es una indagación que solo puede formular quien asume ese sentido misterioso de la existencia, cuya resolución está proyectada hacia el fin del propio tiempo y de todos los tiempos. Esta forma de entender la poesía aparece en sus reflexiones asociada también al papel de la palabra poética como interrogación:

[...] Yo creo que la poesía es interrogación permanente [...] Así, la palabra que interroga encuentra una respuesta que es a su vez otra pregunta que busca, que explora, aunque tenga la apariencia de una aseveración, y esta tropieza con otra interrogación, y así sucesivamente, sin que podamos llegar jamás al fondo total o a la máxima altura. Porque antes de alcanzar el punto más hondo se produce la sofocación y antes del punto más alto, la caída. (Orozco, "Conferencia Universidad de La Pampa": 6)

Desde esta forma de comprender la poesía es posible explicar la presencia de finales que asumen la forma de plegaria o pregunta en tanto modos de exploración y apertura de lo real y de indagación de las claves del yo. 
Paralelamente, los finales en la poesía del Olga Orozco son el resultado de un trabajo minucioso, lento y sumamente cuidado de construir el poema. Se trata de un régimen particular de escritura que explica el paso de su forma privada a su faz pública. Por una parte, el trabajo no es tanto de cincel de una materia globalmente conformada. Por el contrario, es un camino verso a verso, hasta que cada uno adquiere la forma acabada para poder pasar al siguiente:

[Trabajo] muy mucho [el poema] pero casi no tengo que corregirlos al final, porque voy corrigiendo verso por verso a medida que voy escribiendo. $Y$ no paso de una línea a la otra si no la tengo puesta de forma definitiva. Así, cada poema puede llevarme días, pues no se me da la escritura de forma instantánea. Es cierto que soy de largo aliento, de poemas extensos, pero los voy haciendo lentamente. (Piña, 1994: 96)

Por este modo de trabajar el poema, no se observan modificaciones una vez que ha alcanzado el estatuto público. Por ejemplo, entre los anticipos aparecidos en publicaciones periódicas y su edición posterior en libro, no hay variantes ${ }^{3}$.

Para representar esta forma de escribir, Olga Orozco ha empleado varias veces la analogía del poema como casa, sólidamente construida desde sus cimientos, sin contradicciones ni recorridos aberrantes ${ }^{4}$. De este obstinado rigor depende ese efecto de lisura, de desarrollo sin ripios de sus textos que suelen superar el prototipo idealizado del poema como texto breve. Al responder sobre su modo de trabajar durante el proceso de escritura, se observa que el cimiento sobre el que se construye todo el poema es la idea inicial de principio y final. $\mathrm{Al}$ respecto señala:

\footnotetext{
3 Desde la década del '40 los poemas de Olga Orozco circulan primero en publicaciones periódicas: por ejemplo, en Canto, Papeles de Buenos Aires, Sur, por citar solo algunos ejemplos. Ya en los '70, aparecen individualmente o en forma de series poemáticas, especialmente en Cuadernos Hispanoamericanos. En esto, la escritora no es original. Se trata de la forma habitual de circulación de poesía. Lo que sí es representativo de Olga Orozco es el hecho de que entre la versión que circula en publicación periódica y la versión que lo hace en libro, por lo general no hay variantes (o estas variantes son mínimas). Es decir, el texto que adquiere la entidad de público lo hace porque para la autora ya posee el estatuto de definitivo.

4 De los numerosos ejemplos que pueden citarse, transcribo el siguiente: «Creo que hay una estructura, que indica que hay una construcción como la que puede hacer un arquitecto. Yo no escribo nada que no tenga las bases puestas en su sitio, las columnas, las ventanas. Escribo un poema como una casa que voy a habitar, y en la que me voy a mover, sabiendo dónde está cada cosa que necesito, y donde no hay ninguna contradicción, sino las que son manifiestamente buscadas, pero donde un elemento que está en la línea sexta no contradice para nada un elemento que está en la línea 24 . Todo sigue una sucesión coherente». (Sefamí, 1996: 102).
} 
- [...] Mi sistema para escribir es tener el comienzo y el fin de un poema, no sé cómo voy a llegar desde ese comienzo a ese fin, no sé qué camino tengo que recorrer; eso sí se va dando solo.

- ¿Y el final nunca cambia?

- No, casi siempre llegan juntos el principio y el final, sé a donde tengo que llegar; pero el camino no lo sé. Lo que cambia justamente es el recorrido, a veces, pero nunca paso de una línea a la siguiente si la anterior no es la definitiva, es decir, no trabajo el poema cuando está terminado, lo voy trabajando paso a paso. (Sauter, 2006: 119)

Paradójicamente, en el principio del poema está su final. De allí su importancia como marcador de estilo. El trabajo de expansión y de progresión de esa base es, como se ha podido observar, lento. Pero además es tortuoso, tiene un carácter incierto, e implica riesgos y renuncias. Este camino suele representarse en los términos de un viaje o de un pasaje a través de un túnel, tal como se puede observar en el siguiente fragmento de una conversación con Marta Dillon:

- ¿Entonces el final del poema es un alivio?

- Sí, pero no es lo más difícil. Lo arduo es el camino. Tal vez conozca el comienzo y el final también, lo demás es territorio oscuro. Es como un túnel, hay algo que está del otro lado y que alcanzo a ver, una luz al final. Pero mientras cruzo por tembladerales, por veinte mil obstáculos, las solicitudes que encuentro en ese camino son muchas, muchas las imágenes, las historias... Y, en fin, hay que dominarlas y elegirlas porque no se pueden poner todas, entonces sufro una especie de mutilación. El único rescate es lo cotidiano, [...]. (Dillon, 2007)

El sentido arquitectónico que guía la estructuración textual garantiza la impresión profunda de integridad que se percibe en los finales. El poema está dotado de una organicidad que determina que todo lo que se despliega deba reconcentrarse, y que todas las partes se conecten formando una unidad.

A partir de este reconocimiento del final del poema como base del proceso creador y de la asunción de la poesía como plegaria y pregunta se pueden analizar ahora los distintos tipos dominantes en la trayectoria lírica de la poeta. 


\section{Tipología de los finales poéticos en la lírica de Olga Orozco}

Una lectura global del corpus lírico permite advertir la presencia predominante de los siguientes tipos de cierre poético: la sentencia, la interrogación, la profecía y la plegaria ${ }^{5}$. Como ya se señaló, estos tipos están estrechamente relacionados con el carácter oracular y religioso de la lírica de Olga Orozco. Para el análisis de su funcionamiento en el todo poemático, se considerarán variables como la extensión en número de versículos, el tipo ${ }^{6}$, modalidad ${ }^{7}$, el alcance de los enunciados que lo constituyen, su disposición en relación con la organización estrófica, el tiempo verbal en el que se enuncia, su relación con la progresión temática, su carácter abierto o cerrado y los efectos que promueve.

\section{Sentencia:}

Se entiende por sentencia un tipo de final que posee un carácter sapiencial (Aristóteles, 1974; Hegel, 1985; García Berrio, Huerta Calvo,1992). Por ello se inscribe en la modalidad epistémica de la enunciación. La sentencia refiere un saber poseído como certeza por el yo lírico. El contenido de estas sentencias puede involucrar al propio sujeto de la enunciación, al sujeto o al objeto de su evocación poética y en ocasiones puede tener un alcance universal. Este tipo de cierre se caracteriza además por su brevedad y concisión. Su longitud oscila entre un versículo y tres. Puede aparecer adosado al cuerpo de la serie o de la estrofa final en cuyo caso se destaca mediante la autonomía sintáctica, el cambio de modalidad del enunciado u otros marcadores discursivos. En otras ocasiones puede aparecer separada mediante el blanco y conformar una estrofa independiente.

La sentencia sintetiza los ejes temáticos desplegados en el poema. Adopta la forma de un enunciado afirmativo, generalmente en tiempo presente (aunque a veces, el verbo puede estar elidido). Desde el punto de vista de la

\footnotetext{
5 Sin embargo, es posible encontrar poemas que no tienen estos tipos de final. Por eso se habla de una ocurrencia predominante.

6 Afirmativo, interrogativo, imperativo.

7 Entendemos con Pottier que las modalidades «[...] expresan la posición del enunciador con relación a su propósito» (1992: 126 y ss). Pottier distingue entre las modalidades referidas a la existencia o existenciales en las que incluye la óntica (no ser/ parecer/ ser) y la alética (imposible/ posible/ necesario - inevitable); al conocimiento o epistémicas (ignorar/ suponer - presumir/ creer/ saber); factuales referidas a los hechos, el decir y el hacer; y axiológicas, referidas a los juicios de valor (283-289).
} 
enunciación, suele aparecer sin ningún tipo de marca modalizante. Por esta razón suscita en el lector el efecto de un dictamen inapelable ${ }^{8}$. Así se observa, por ejemplo, en "Al pie de la letra":

El tribunal es alto, final y sin fronteras.

Sensible a las variaciones del azar como la nube o como el fuego, registra cada trazo que se inscribe sobre los territorios insomnes del destino.

De un margen de la noche a otro confín, del permiso a la culpa, dibujo con mi propia trayectoria la escritura fatal, el ciego testimonio. Retrocesos y avances, inmersiones y vuelos, suspensos y caídas componen ese texto cuya ilación se anuda y desanuda con las vacilaciones, se disimula con la cautela del desvío y del pie sobre el vidrio, se interrumpe y se pierde con cada sobresalto en sueños del cochero. ¿Y cuál será el sentido total, el que se escurre como la bestia de la trampa y se oculta a morir entre oscuras malezas dejándome la piel o huye sin detenerse por los blancos de las encrucijadas, laberinto hacia adentro? Delación o alegato, no alcanzo a interpretar las intenciones del esquivo mensaje.

Difícil la lectura desde aquí, donde violo la ley y soy el instrumento, donde aciertos y errores se propagan como una ondulación, un vicio del lenguaje o las disciplinadas maniobras de una peste, y cambian el color de todo mi prontuario en adelante y hacia atrás. Pero hay alguien a quien no logra despistar la ignorancia, alguien que lee aún bajo las tachaduras y los desmembramientos de mi caligrafía mientras se filtra el sol o centellea el mar entre dos líneas. Impresa está con sangre mi confesión; sellada con ceniza. (Orozco, 1983: 38)

\footnotetext{
8 Los poemas que presentan este tipo de cierre son los siguientes: "La abuela", "Lejos, desde mi colina", de Desde lejos; “Las muertes", "Maldoror", "Evangelina”, "Olga Orozco", de Las muertes; "Repetición del sueño", "El adiós", "Para hacer un talismán", "La caída", "Llega en cada tormenta", “Sol en Piscis", “En donde la memoria es una torre en llamas", "Desdoblamiento en máscara de todos", de Los juegos peligrosos; "El jardín de las delicias", "Duro brillo, mi boca”, de Museo salvaje; "Canto I", de Cantos a Berenice; "Presentimientos en traje de ritual", "La realidad y el deseo", "Bloques al rojo, bloques en blanco", "Los reflejos infieles", "Continente vampiro", "El revés de la trama", "Atavíos y ceremonial", "Densos velos te cubren, poesía", de Mutaciones de la realidad; "Esbozos frente a un modelo", "No han cambiado y son otros", "No hay acceso", "Para este día", “Con el humo que no vuelve", "Botines con lazos de Vincent van Gogh", "Al pie de la letra", "El presagio", de La noche a la deriva; "En el laberinto", "Al pájaro se lo interroga con su canto", "El resto era silencio", "Fundaciones de arena", de En el revés del cielo; "La mala suerte", “¿Quién, quién, quién?", de Con esta boca, en este mundo; "En el fondo, el sol”, "Vuelve cuando la lluvia" Últimos poemas. Para una lectura global de la poesía remito a Orozco. 2012. Los poemas citados en el estudio se recogen de sus primeras ediciones.
} 
En esta alegoría del yo, la propia vida se representa metafóricamente como una escritura que sólo puede ser interpretada por un enigmático "alguien" (¿Dios?), quien goza de una visión privilegiada9. El reconocimiento de la dicotomía entre la ignorancia del sujeto de la enunciación y la sabiduría de esa instancia superior, organiza el despliegue temático del poema. Las oposiciones tienen un valor polar mediante el cual se intenta abarcar la totalidad de las instancias vitales («De un margen de la noche a otro confín, del permiso a la culpa...»; «Retrocesos y avances, inmersiones y vuelos, suspensos y caídas...»; «Delación o alegato...»; «....aciertos y errores se propagan como una ondulación...»).

La progresión temática sigue un itinerario que va desde el desconocimiento personal hasta el conocimiento de Dios. Este giro argumentativo prepara el desenlace final. La sentencia se destaca mediante la autonomía sintáctica. Su valor sapiencial afecta directamente al sujeto de la enunciación. Su condición jurídica de dictamen inapelable ha sido preparada por los índices figurativos de todo el poema (tribunal, permiso, culpa, testimonio, dilación, alegato, ley, prontuario, confesión). La sentencia cierra drásticamente la arquitectura argumentativa del poema. Este cierre posee además un carácter oracular. La palabra del poeta «no muestra ni oculta" y sus señales se contentan con confirmar la dicotomía planteada inicialmente: la ignorancia del yo frente a la sabiduría de ese otro misterioso. Se trata de una constatación patética subrayada discursivamente mediante la concisión de la frase.

En otras ocasiones, la sentencia repite parcial o totalmente un segmento del texto que opera como leit motiv. Por tal razón, su efecto estético es semejante al del cierre mediante un estribillo. Entre los poemas que adoptan este tipo de cierres se encuentran, por ejemplo, "La abuela" de Desde lejos y "La realidad y el deseo" de Mutaciones de la realidad.

El mensaje de la sentencia puede circunscribir su alcance al sujeto de la enunciación, como en "Al pie de la letra" o referirse al sujeto evocado como por ejemplo en "La abuela". En otras ocasiones, por ejemplo "No han cambiado y son otros" de La noche a la deriva, la sentencia de cierre se postula como máxima de carácter universal. Temáticamente, este texto guarda rela-

9 La visión de la vida como escritura (poema o relato) vuelve a aparecer en la lírica de Olga Orozco en el poema "El narrador", de En el revés del cielo. 
ción con "La abuela". En él, la escritora efectúa una nueva evocación de sus ancestros desaparecidos. La paradoja planteada en el título alude a un modo particular de comunicación entre vivos y difuntos. Señala formas alternativas de manifestación de los seres arrebatados por la muerte. También, el modo en que la memoria permite interpretar estas formas de manifestación.

El poema se estructura en estrofas de extensión semejante. Las tres primeras corresponden, respectivamente, a la evocación de la abuela, la madre y el padre. La estrofa final confirma su comunicación efectiva con el sujeto lírico del siguiente modo:

Ellos vuelven y ocupan sus lugares junto a estas ventanas, esta mesa, este lecho; vuelven con grandes trozos de paredes y muebles y paisajes disueltos y construyen con ellos extraños escenarios que intercalan a través de los años. No han cambiado y son otros: compartieron conmigo los fulgores y los rasguños de este lado.

No han cambiado y son otros: una opaca polilla, un objeto que cae, la rama que golpea contra el vidrio, este frío que corre por mi cara.

Es posible que intenten como yo la aventura de violentar el tiempo, de mezclar las barajas del presente, del porvenir y del pasado.

No han cambiado y son otros.

No es museo de cera la memoria. (Orozco, 1983: 31-32)

En este pasaje, el título se repite tres veces como un leit motiv enfático que prepara el final del poema. La última repetición introduce la sentencia («No es museo de cera la memoria»). No hay marcas modalizantes del enunciado ni de la enunciación. Por esta razón, la sentencia posee un valor terminante y universal. La poeta profundiza con esta afirmación el sentido de la memoria como un espacio dinámico, de redención de los seres contra la acción del tiempo ${ }^{10}$.

\footnotetext{
10 Olga Orozco concibe la memoria de diversas maneras. En la conferencia "Tiempo y memoria", destaca que no la concibe solo como un espacio de almacenamiento pasivo, sino de acción incesante y circular: «No es entonces esa melancólica añoranza de brazos caídos que llamamos nostalgia, sino una memoria viviente y ávida, que se encarna y reencarna para descubrir, para perseguir significaciones como por primera vez». (Orozco, 1993: XIV). Para las transformaciones en la concepción de la memoria en la obra de la autora puede verse también Zonana. 2003.
} 


\section{Interrogación:}

Otro tipo de cierre poético frecuente en la lírica de Olga Orozco es la interrogación ${ }^{11}$. Esta modalidad enunciativa posee un lugar propio en la retórica clásica, particularmente en aquellas formas de la aversio y de la immutatio syntactica que implican una apelación al orador, al objeto del discurso o al oyente (Apostel, 1981; Gadamer, 1984; Lausberg, 1975; Meyer, 1993; Molinié, 1992; Spang, 1984). Entre ellas se pueden mencionar la interrogación retórica y la communicatio ${ }^{12}$. En estos casos, sin embargo, la modalidad interrogativa constituye sólo una máscara discursiva. La pregunta se halla despojada de su sentido real de apertura y de su fuerza ilocucionaria. En efecto, la interrogación retórica no pregunta, es decir no inquiere una respuesta ya sea porque ella está dada por la fuerza de las evidencias o porque el discurso ya la contiene en su totalidad (Lausberg, 1975: 217; Spang, 1984: 201).

No es este el sentido de los finales interrogativos de la lírica orozquiana. Por el contrario, éstos cumplen, como destaca Gadamer, el objetivo de abrir una cuestión (1984: 369). Esta funcionalidad distintiva de la pregunta representa una marca de la contemporaneidad del discurso de Olga Orozco. En su universo literario, la interrogación final posee una relación muy estrecha con la concepción de la poesía como modo de conocimiento, tal como se señaló anteriormente. Es la manifestación más explícita de la pregunta por el misterio de la realidad en sus múltiples planos. Su persistencia está determinada por la condición siempre enigmática de este objeto asediado en el poema. También, por el apremio del sujeto lírico en la búsqueda de respuestas.

El final interrogativo no implica una ceguera absoluta. Revela, sí, la posesión de un conocimiento enigmático. De un mensaje en clave que intenta

\footnotetext{
11 Los poemas que adoptan este tipo de cierre son los siguientes: "Gail Hightower", de Las muertes; "Para ser otra", "Entre perro y lobo", de Los juegos peligrosos; "Lamento de Jonás", "Mis bestias", "Parentesco animal con lo imaginario", "El sello personal", "Tierras en erosión”, de Museo salvaje; Cantos "IV", "X", "XI" y "XIV", de Cantos a Berenice; "Operación nocturna", de Mutaciones de la realidad; "Parte de viaje", "Cantata sombría", de La noche a la deriva; "Muro de los lamentos", "El narrador", "¿Lugar de residencia?", "Ceremonia nocturna", "Punto de referencia", "Fuera de foco", de En el revés del cielo; "Con esta boca, en este mundo", "Pequeños visitantes", "Miradas que no ven" de Con esta boca, en este mundo; "Himno de alabanza", "Algunas anotaciones alrededor del miedo", "Lo que fue, lo que no ha sido" de Últimos poemas.

12 Pregunta dirigida a un interlocutor (real del auditorio o ficticio en el discurso) en la que se solicita un consejo (ficticio y deliberativo) respecto a la manera de obrar (en el pasado, en el presente o en el futuro). Se trata de una pregunta simulada porque el orador ya ha tomado su decisión, pero involucra a su auditorio a través de la pregunta (Lausberg, 1975: 220).
} 
descifrarse. El que pregunta, demanda por el sentido último de aquello que posee. Si todo lo ignorara, no podría preguntar. Si lo supiera todo, no necesitaría hacerlo (Apostel, 1981: 23; Gadamer, 1984: 453). De este modo, en la lírica de Olga Orozco el cuerpo textual que precede a la pregunta corresponde a ese espacio del conocimiento ya conquistado. Su función argumentativa y estética consiste en revelar la orientación de la pregunta y, paralelamente, desplegar el horizonte hermenéutico que le da sentido (Gadamer, 1984: 439). La pregunta abre el ser de aquel contenido que ha sido presentado en el texto antes de ser formulada.

Por estas razones, la pregunta en la lírica de Olga Orozco no es "retórica" ya que su respuesta no puede darse por fuerza de las evidencias, ni su contenido está agotado totalmente en el discurso. Además, es siempre metafísica o escatológica. Es decir, inquiere por los fundamentos del ser o por su futuro más allá de la existencia. De este sentido de la interrogación final se desprende su fuerza ilocucionaria. La pregunta busca transformar un estado de conocimiento (Apostel, 1981: 24), aunque de hecho la escritora manifieste la imposibilidad de esta tentativa, dada la condición del poema como revelación frustrada. De aquí deriva el carácter suspensivo de este tipo de finales. La suspensión del ánimo es correlativa de los estados cognitivos y afectivos que se revelan mediante la pregunta. Entre ellos, la duda, el extrañamiento y la impotencia. Los finales interrogativos corresponden al polo negativo de las modalidades epistémicas de la enunciación en el discurso de Olga Orozco. Articulan las relaciones entre "creer", "saber" e "ignorar". Representan la situación del sujeto lírico enfrentado a la aporía y la irresolución.

Este tipo de cierres es también índice de intersubjetividad (Apostel, 1981: 23). La pregunta se dirige al lector, implicándolo en la búsqueda de conocimiento a través del poema. Pero también se dirige al yo, en los poemas que adoptan el dialogismo, a los seres arrebatados por la muerte o a Dios. En las diversas actitudes que adopta el sujeto lírico al dirigirse a los otros se manifiesta la distancia que lo separa de sus interlocutores (Meyer, 1993: 77). En los casos en que la interrogación final implica una apelación a un interlocutor individualizado podría ser confundida con la plegaria. Sin embargo, se distingue de ella por la modalidad interrogativa del enunciado y porque generalmente no implica una secuencia de acciones a realizar por el interlocutor. 
Desde el punto de vista de la organización formal, la interrogación puede aparecer integrada a la serie o a la estrofa final. También puede constituir una estrofa en sí misma. La extensión de este tipo de cierres oscila entre uno y cuatro versículos. Si en una serie o una estrofa una interrogación es precedida por otras, aquella que oficia verdaderamente de final es marcada discursivamente mediante el cambio de sujeto del enunciado.

La interrogación suele aparecer en la lírica de Olga Orozco también en el cuerpo del poema. Sin embargo, allí posee otra finalidad. Habitualmente, plantea interrogantes que son resueltos en los enunciados asertivos que les siguen. En este caso, las preguntas representan las distintas fases de la argumentación poética, tal como se refleja en el poema "El jardín de las delicias" de Museo salvaje.

Como tipo conclusivo, la interrogación se manifiesta en el universo literario de Olga Orozco a partir de Las muertes.

Un excelente ejemplo de cierre interrogativo se encuentra en la última estrofa del poema "Para ser otra":

[...] ¿Y este nombre secreto con que me nombran todos y se nombran? Ya soy ajena a mí, pero es el mundo entero quien emigra conmigo como un solo organismo arrebatado de cada cautiverio, de cada soledad, por esa bocanada de las grandes nostalgias.

$\mathrm{Y}$ de pronto, ¿este desgarramiento, esta palpitación en medio de la noche que corta su atadura en la vena más honda de la tierra, este fondo de barca que asciende sobre un lecho de plumaje celeste, este portal aún entre la niebla, este solo recuerdo del porvenir desde el comienzo de los siglos? ¿Quién soy? ¿Y dónde? ¿Y cuándo? (Orozco, 1962: 28)

De esta manera la poeta concluye con el juego de probarse otras personalidades. El retorno a la individualidad originaria, último paso del juego, muestra la precariedad de este espacio. El yo se ha enajenado progresivamente ya que en su complexión se adhirieron constituyentes de las personalidades asumidas. La importante enumeración paralelística y anafórica que se inicia en el sexto versículo, discrimina los constituyentes de la otredad ins- 
criptos en el yo. El carácter predominantemente interrogativo de la estrofa es un índice estilístico de la incertidumbre del propio sujeto con respecto a su identidad. El último versículo expresa el nivel máximo de extrañamiento. En él se efectúa una interpelación radical de las tres coordenadas que permiten anclar la personalidad: el tiempo, el espacio y el yo. El sujeto de la enunciación revela de esta manera la intemperie total de su ser: el despojamiento del nombre y de la identidad. Toda la progresión temática del poema conduce a esta aporía final. Se trata de un momento en el cual la ontología de la subjetividad es abierta plenamente en la pregunta. Ésta ya no puede responderse por las claves co-textuales ni contextuales. Desde un punto de vista pragmático, si bien la pregunta es aquí índice de autorreflexión, se proyecta en el lector. Por su fuerza ilocucionaria lo invita a participar del cuestionamiento que se efectúa en todo el poema.

En "Para ser otra" la pregunta final se dirige al propio yo. Conviene examinar ahora un caso en el que la pregunta final es dirigida a otra persona, resaltando así su condición intersubjetiva. Por ejemplo, el poema "Punto de referencia" de En el revés del cielo:

He acumulado días y noches con amor, con paciencia - ah, con ira también, un resplandor de tigres en la oscura desdicha -; los he petrificado alrededor del sitio donde habito, que no es más que una pálida espesura en medio de la enrarecida vastedad, una exigua sustancia expuesta a los pillajes y a la furia desatada del tiempo. He juntado vestigios, testimonios que acreditan quién soy, credenciales irrefutables como un juego de espejos en torno de un fulgor, certezas como cifras esculpidas en humo.

Puedo afirmar que no hay bajo este cielo nada que no perdure por mis ojos y que un ínfimo insecto conserva su lugar de honor en mi muestrario.

No soy menos que un topo; algo más que una hierba.

Sin embargo no encuentro mi verdadera forma ni aun a plena luz, por más que me recuente, me recorra y persiga por fuera y por debajo de la piel. Siempre hay alguien en mí que dice que no estoy cuando me asomo, alguien que se desliza paso a paso a medida que avanzo hasta dejarme a ciegas, asida solamente a un nombre, a la ignorancia. Porque hay prolongaciones inasibles que llegan más allá, zonas inalcanzables donde tal vez se impriman las pisadas de Dios, subsuelos transparentes que se internan a veces en los jardines de otro mundo 
y al regresar expanden un perfume semejante al del alba.

¿Y esos bloques errantes, continentes en fuga como ballenas blancas

que rozan las fronteras propagando el pavor y no regresan nunca?

¿Y qué fronteras rozan, si he forzado hasta el máximo la vista y el

insomnio

y donde me aventuro no hago pie, me pierdo en los abismos?

¿No he arrojado preguntas como piedras y amores como escombros

que están cayendo aún, que no han tocado fondo todavía?

Inmenso mi animal desconocido, mi armazón insondable, mi esfinge nebulosa.

Y ningún emisario, ningún eco, que no sea este cuerpo inacabado.

Toda una confabulación de lo invisible para indicar apenas que no soy de este mundo, sino sólo un testimonio adverso contra la proclamada realidad, una marca de exilio adherida a las grandes cerrazones donde comienza el alma, acaso con un himno, quizás con un sollozo.

Pero dime, Señor:

¿mi cara te dibuja? (Orozco, 1987: 101-102)

La voz enunciadora busca un punto de referencia para comprenderse. Esta búsqueda se representa como una acumulación de pruebas que atestigüen en favor del yo. Sin embargo, la condición incierta de tales testimonios impide fundar la personalidad sobre bases sólidas. Tal es el sentido del oxímoron comparativo en los versículos séptimo y octavo: «...credenciales irrefutables como un juego de espejos en torno de un fulgor,/ certezas como cifras esculpidas en humo».

La progresión temática coincide con el encarecimiento de estas paradojas a las que se enfrenta el yo en su tarea de exploración y reconocimiento. Este proceso implica el paso de lo próximo, lo propio y lo terrenal a lo lejano, al no yo, a lo trascendente («Siempre hay alguien en mí que dice que no estoy cuando me asomo...»). Ante la presencia de rasgos que atestiguan otro origen, otro espacio de pertenencia, crece el asombro. Hasta abismarse y explicitarse metafóricamente. El preguntar poético se cristaliza: «¿No he arrojado preguntas como piedras y amores como escombros/ que están cayendo aún, que no han tocado fondo todavía? ». La pregunta/ piedra quiere romper el sello del misterio. Pero el resultado de la indagación es exiguo. Sólo permite 
presentir que la existencia, este "revés del cielo", reclama por su lado dere$\mathrm{cho}^{13}$. Este reclamo por la propia dimensión trascendente conduce a la pregunta final, dirigida al único interlocutor que puede ofrecer una respuesta.

El blanco desempeña un papel capital en la progresión temática. Representa el giro de la argumentación previo a la apelación al interlocutor. Connota el tiempo y el valor que debe tomar el yo lírico para formular su demanda.

La pregunta es un intento por profundizar el sentido de la relación entre el yo y Dios. Por escudriñar el valor de la imagen y la semejanza. El interrogante queda abierto. Su apertura descubre el horizonte de la pregunta. Un horizonte sincrético que incorpora la idea gnóstica de Dios como ser desgarrado, como ser incompleto que ha de cumplirse en un futuro, cuando reintegre en sí a cada una de sus criaturas (Mujica, 1988: 1089).

\section{Profecía:}

Un tercer tipo de final dominante en el universo lírico de Olga Orozco adopta la forma de una secuencia orientada hacia el futuro. En analogía con el género bíblico, se puede categorizar como profecía (Sicre, 1992; Steiner, 1980; Criado de Val, 1992; Alarcos Llorach, 1993: 149 y ss; Pottier, 1992: 229 y ss.). Como la sentencia, la profecía posee el carácter de un conocimiento inapelable. Generalmente, se presenta con el estatuto de una ley que será acatada inexorablemente, ya sea porque ha sido establecida por Dios, ya porque corresponde a un aspecto inherente a la naturaleza del sujeto lírico o del objeto de su poema. Por esta razón la profecía se expresa mediante enunciados asertivos.

Sin embargo, en la medida en que el final profético anuncia eventos prospectivos con relación al presente de la enunciación -es decir, no realizados todavía -, su efecto estético es semejante al de la interrogación: la tensión cognitiva y afectiva es dejada en suspenso.

Como secuencia de cierre, la profecía constituye una suerte de revelación: anticipa un futuro que se desea o que se prevé como inevitable. Se trata de una anticipación asociada con juegos de condensación temporal ya que la

13 Esta es la sabiduría expresada de manera insistente en el libro. Como destaca María Rosa Lojo, en él Olga Orozco parece demostrar que «[...] nunca las antinomias son absolutas, totales. Invisibles hilos unen uno y otro lado del espejo, del tapiz; cielo y tierra [...] mantienen una comunicación secreta» (Lojo, 1988: 3). 
visión de lo por venir presupone la posibilidad de adoptar una mirada panorámica de los acontecimientos, fuera del tiempo. Esta posibilidad se da en el espacio de la literatura.

En una gran proporción, los poemas que adoptan este tipo de cierre desarrollan isotopías temáticas vinculadas con el fin de la existencia ${ }^{14}$. Por eso sus enunciados tienen una modalidad existencial relativa al ser del sujeto de la enunciación o de los sujetos evocados en el poema a quienes se aplica la profecía. Son cierres que presentan en lo temático, lo figurativo y lo formal, una mayor autonomía secuencial que los tipos anteriores. Propiedad relacionada con su extensión (que puede oscilar de uno a nueve versículos). Estilísticamente, la amplitud de la sentencia profética es proporcional a su carácter enfático.

La profecía final puede aparecer adosada a la serie o a la estrofa. También puede conformar una estrofa independiente. Como modalidad de cierre aparece tempranamente en la lírica de Olga Orozco. En Desde lejos constituye un tipo frecuente.

El inicio del cierre profético puede estar marcado léxicamente. En estos casos, el sujeto de la enunciación es consciente de ser transmisor de una palabra ajena ${ }^{15}$. Sin embargo, el marcador fundamental de la sentencia profética es la presencia de un verbo en futuro simple de indicativo como núcleo de la oración principal de la secuencia (o de una forma perifrástica que exprese la misma perspectiva temporal como por ejemplo /ir + a/, / haber + de/, con la misma función).

El sentido profético está determinado por el particular uso del futuro en estas secuencias. Habitualmente, el futuro es el tiempo que sirve para referirse a un plano de existencia virtual (Pottier, 1992: 234). En los usos científico y cotidiano, el futuro puede hacer referencia a mundos hipotéticos, utópicos, subjetivos, irreales o deseables. Por el contrario, en los usos oraculares

14 Los poemas que concluyen con profecías son los siguientes: “Quienes rondan la niebla”, “Un pueblo en las cornisas", "Un rostro en el otoño", "Después de los días", "Donde corre la arena dentro de corazón", "Cuando alguien se nos muere", de Desde lejos; "Noica", "James Waitt", "La víspera del pródigo", de Las muertes; "Espejos a distancia", "Día para no estar", "Habitación cerrada", "Feria del hombre", de Los juegos peligrosos; "Detrás de aquella puerta", de La noche a la deriva; "El obstáculo", "El retoque final", de En el revés del cielo; "La corona final", "Con la misma piel”, de Con esta boca, en este mundo.

15 Como ocurre generalmente en la Biblia (Sicre, 1992 : 109). 
o proféticos, el futuro expresa una conciencia compleja de la temporalidad. Puede revelar la presencia de un fatum no previsto, pero siempre presente $\mathrm{y}$ al acecho; o el advenimiento de un evento favorable, si se respeta el plan de la Providencia o del "orden natural" y de uno desfavorable en la medida en que se transgrede dicho plan. Por esta razón George Steiner caracteriza esta forma de temporalidad como "futuro-presente". Según su opinión, el oráculo griego y la profecía bíblica son dos caras de esta forma compleja de concebir y representar el tiempo. Al respecto señala:

Un respeto absoluto de la alianza, una rigurosa observancia de la ley, pone a la casa de Jacob en armonía con todo lo que lo desconocido tiene de 'natural'. O, para decirlo de otro modo, lo 'desconocido' del futuro pierde toda su importancia, se vuelve ontológica y éticamente trivial. Sólo cobra una coloración verdadera y tangible, ya sea de amenaza, ya sea de ilusión, en virtud del fracaso humano, de sus errancias y apartamientos de la ley. No hay ninguna amenaza, ninguna lamentación del profeta que no esté contenida de antemano y por completo en el acto de la transgresión. Como también lo está la promesa divina de un futuro susceptible de ser revocado o retenido. (...) Los futuros condicionales de la profecía bíblica contrastan tajantemente con lo que bien podría llamarse la ambigua fatalidad del oráculo griego. El oráculo, por lo menos durante las primeras etapas de la historia griega, nunca se equivoca. [...] Los futuros del oráculo manifiestan un rígido determinismo. Aquí, como en la gramática de la maldición, las palabras no pueden revocarse, ni alterarse los desenlaces de la fatalidad. (Steiner, 1980: 173-174)

Esta oscilación en el sentido del futuro se presenta en los cierres proféticos de la poesía orozquiana. Expresan alternativamente el acatamiento de una ley inexorable o la posibilidad de una futura recuperación de la unidad primordial ${ }^{16}$.

Los eventos futuros, anticipados mediante el cierre profético, presentan distintos grados de alejamiento con relación al presente de la enunciación (Criado de Val. 1992, 141). Las secuencias proféticas que utilizan la perífrasis /ir + a/, señalan un evento próximo con respecto al presente de la enunciación. Aquellas que emplean el futuro simple de indicativo o la perífrasis / haber + de/ remiten a eventos lejanos.

16 Al respecto creo importante señalar que la recuperación de la unidad se manifiesta con mayor frecuencia en los poemas de Desde lejos y en algunos poemas de los últimos libros. En el resto de la producción de Olga Orozco parece dominar una conciencia trágica del fatum. 
Por ejemplo, en "Donde corre la arena dentro del corazón" de Desde lejos, el yo lírico reflexiona sobre los profundos vínculos del hombre con su espacio. En el entorno pampeano, los médanos ponen ante sus ojos el espectáculo de una constancia en la devastación. Serenamente, la poeta revela que este poder de la tierra ha penetrado el corazón del hombre. Así, en las últimas estrofas este terrible nexo con el espacio determina el regreso de aquellos que, temporariamente, abandonan el terruño:

[...] Desmedida es la tierra que amó en sus duros hijos hasta la destrucción,

hasta la sal paciente de su sangre;

mas de ella aprendieron a contemplar la vida a través de la muerte, a saber, sin reposo, que aún no ha sido creado aquello que

no puedan sobrellevar las almas de los hombres,

y a comprender que el cielo y el infierno son expiados aquí con opacas desdichas.

Si ellos se marchan hoy, si hoy sus pueblos emigran a lo largo de una seca planicie donde antaño crecieron junto a las mismas casas, con árboles, pesares y costumbres, no es preciso volver la vencida cabeza en despedida, no es preciso dejar señales de sus pasos que reciban después sus propios pasos.

Ellos regresarán, porque así lo dispone un lamento de arena que responde al llamado natal de otras arenas, allá, en el más abismado eco del corazón. (Orozco, 1946: 47-48)

La estrofa final aclimata al espacio pampeano la célebre sentencia ritual del miércoles de ceniza: recuerda hombre que eres polvo y al polvo volverás. La profecía se halla determinada por la enseñanza de la madre-tierra que prepara el periplo vital de sus hijos, su "retorno al polvo". De allí la certeza del yo lírico, enfatizada en la penúltima estrofa mediante las anáforas de los versos finales («...no es preciso volver la cabeza en despedida,/ no es preciso dejar señales de sus pasos..."). Por su condición terrestre, el hombre se halla destinado indefectiblemente a reintegrarse con su espacio natal en un 
futuro lejano o al menos no determinable (marcado léxicamente con el futuro simple de indicativo con que se inicia la última estrofa). La profecía se erige como certeza. Certeza que se desprende de la vivencia de la ley inexorable de la muerte que determina la orientación del ciclo vital.

Por otra parte, se observa en el cambio de tiempos verbales de las dos últimas estrofas una importante condensación. El hoy del abandono es circunstancial ya que el vínculo establecido con el espacio en el pasado promueve la reintegración futura con la tierra.

Un ejemplo distinto se encuentra en el poema "Espejos a distancia". El símbolo del espejo le permite a la escritora desarrollar desde otra perspectiva la problemática del yo plural. En este caso, la isotopía figurativa del reflejo se corresponde con el eje temático que contrapone el yo de la existencia al yo de la trascendencia. Hacia el final de la sección III del poema, esta contraposición se plantea en los siguientes términos:

[...] Yo no entiendo esta piel con que me cubren para deshabitarme.

No comprendo esta máscara que anuncia que no estoy.

¿Y estos ojos donde está suspendida la tormenta?

¿Esta mirada de ave embalsamada en la mitad de su vuelo?

¿He transportado años esta desolación petrificada?

¿La he llevado conmigo para que me tapiara como un muro la tierra prometida?

Entonces, este cuerpo ¿habrá estado tal vez tan lejos de la vida como ahora está lejos de su muerte?

Sin embargo la tierra en algún lado está partida en dos;

en algún lado acaba de cambiarse en una cifra inútil sobre las tablas de la revelación;

en algún lado, donde yo soy a un tiempo la esfinge y la respuesta.

Que se calle mi nombre en esa boca como en un sepulcro.

Voy a empezar a hablar entre los muertos.

Voy a quedarme muda. (Orozco, 1962: 18)

En esta sección la isotopía temática del yo escindido se combina con la de la corporalidad. El cuerpo es visto como un espacio que se interpone entre las dos imágenes del yo. Como la superficie material del espejo, el cuerpo («muro que tapiza la tierra prometida») impide al yo introducirse en el mundo del más allá que se proyecta en su reflejo trascendente. 
El cuerpo es también la instancia que determina el futuro próximo del yo. En los versículos que constituyen la profecía este carácter de proximidad se expresa mediante el aspecto incoativo de la perífrasis verbal. El anuncio certifica una condición que la corporalidad inscribe en la naturaleza del individuo: la muerte. El interés de la escritora ya no consiste en anticipar, mediante el presente de su enunciación, un futuro lejano y anhelado. Antes bien, se orienta a constatar un evento inherente e inevitable de la existencia. El aspecto incoativo, al connotar una acción que comienza a realizarse, determina el final abierto del poema. La tensión cognitiva y afectiva del lector queda suspendida.

\section{Plegaria:}

Un último tipo dominante de cierre poético es el que corresponde a la plegaria $^{17}$. La plegaria aparece frecuentemente como cierre de elegías funerales. Presupone generalmente la identificación de los interlocutores concretos a quienes se les solicita que cumplan una serie de acciones. Estas acciones se orientan a restablecer un vínculo interrumpido por la muerte. La solicitud puede estar dirigida al sujeto de la evocación poética (Berenice en el "Canto XVII", Alejandra Pizarnik en "Pavana para una infanta difunta", Francesco Stella en "Crónica entre dos ríos"); a Dios ("Espejo en lo alto"); o a un auditorio particular (al que generalmente se le pide la compasión), identificado en el texto mediante diversas marcas léxico-figurativas ("El extranjero", "El pródigo").

Como los otros tipos de cierre, la plegaria puede aparecer inserta en el cuerpo de la serie o de la estrofa final, o puede conformar una estrofa independiente separada mediante el blanco.

El marcador discursivo que permite identificar el inicio de una plegaria es la presencia de verbos en modo imperativo o en presente del subjuntivo. En algunas ocasiones, como sucede por ejemplo en "Catecismo animal" o "En la brisa, un momento", estas formas de la demanda se sustituyen por verbos

\footnotetext{
17 "Un rostro en el otoño", "La desconocida” Desde lejos; “El extranjero", “...Lievens", "James Waitt” y "El pródigo" Las muertes; "XVII" Cantos a Berenice; "Pavana para una infanta difunta" Mutaciones de la realidad; "En tu inmensa pupila", "Recoge tus pedazos", "Por mucho que nos duela", La noche a la deriva; "Catecismo animal", "La sibila de Cumas", “Tierra nueva en crónica vieja" En el revés del cielo; "Espejo en lo alto", "En la brisa, un momento", "Les jeux sont fait" Con esta boca, en este mundo; "Balance de la sombra", "Había una vez" últimos poemas.
} 
performativos en presente de indicativo ${ }^{18}$ que incluyen en su composición el sema / petición/. Entre ellos, "pedir", "reclamar", "apelar", "abogar", etc. Los enunciados de este tipo de cierre corresponden a la modalidad factual.

Los finales con la forma de plegaria presentan una mayor variabilidad en cuanto a su extensión. Pueden alcanzar hasta doce versículos. En los casos en que la plegaria coincide con la totalidad del texto, el sentido de cierre está dado por la última secuencia que presenta un verbo de petición en función de núcleo de la oración principal. Buen ejemplo de esta situación es el poema número XVII de Cantos a Berenice:

Aunque se borren todos nuestros rastros igual que las bujías en el amanecer y no puedas recordar hacia atrás, como la Reina Blanca, déjame en el aire la sonrisa.

Tal vez seas ahora tan inmensa como todos mis muertos y cubras con tu piel noche tras noche la desbordada noche del adiós: un ojo en Achernar, el otro en Sirio, las orejas pegadas al muro ensordecedor de otros planetas, tu inabarcable cuerpo sumergido en su hirviente ablución, en su Jordán de estrellas.

Tal vez sea imposible mi cabeza, ni un vacío mi voz;

algo menos que harapos de un idioma irrisorio mis palabras.

Pero déjame en el aire la sonrisa:

la leve vibración que azogue un trozo de este cristal de ausencia, la pequeña vigilia tatuada en llama viva en un rincón, una tierna señal que horade una por una las hojas de este duro calendario de nieve.

Déjame tu sonrisa a manera de perpetua guardiana, Berenice. (Orozco, 1977: 73-74)

Con este canto concluye el ciclo de Berenice. La intensidad del recuerdo es subrayada mediante el sintagma «déjame en el aire la sonrisa». De él depende el carácter de plegaria del canto. Este leit motiv se repite al principio, en la mitad y en el final del texto. Oficia de elemento estructurador básico. Cabe destacar que la frase remite transtextualmente al capítulo sexto "Sal

\footnotetext{
18 Los verbos performativos o "realizativos" son aquellos empleados en enunciados cuya función específica es cumplir la acción que enuncian. Por ejemplo: "Os declaro marido y mujer", "Te prometo que tomaré el remedio", "Sí, juro" (Austin, 1990).
} 
y pimienta" de Alicia en el país de las maravillas (Carroll. 1982, 101-114). La imagen de la sonrisa que permanece en el aire corresponde a la enigmática desaparición del gato de Cheshire. En su nuevo co-texto, pierde las connotaciones enigmáticas y burlescas del original y adquiere un tono melancólico.

El sentido de cierre poético está determinado por la variación del sintagma en los últimos tres versículos. La presencia del deíctico "tu" y del nombre propio son los responsables del efecto de acercamiento hacia el sujeto evocado.

\section{Observaciones finales}

A partir del reconocimiento del final del poema como problema teórico desde una perspectiva poética, discursiva y cognitiva, se ha procedido al análisis de los finales en el corpus lírico de Olga Orozco. Primeramente, se ha reconocido su relación con formas de entender la poesía como plegaria e interrogación. Luego, a partir de sus reflexiones sobre sus prácticas de escritura, se ha identificado la importancia del final como punto de partida de la escritura total del poema. Finalmente, el recorrido por el corpus ha permitido identificar cuatro formas dominantes de finales poéticos: sentencia, interrogación, profecía y plegaria.

Los finales han sido examinados de acuerdo con su extensión, el tipo, modalidad y alcance de los enunciados que lo constituyen, su disposición en relación con la organización estrófica, el tiempo verbal en el que se enuncian, su relación con la progresión temática, su carácter abierto o cerrado y los efectos que promueve. En cuanto a la extensión, se ha visto que la forma más breve es la de la sentencia y la más extensa, la plegaria. Los tipos de enunciados que predominan son afirmativos, interrogativos e imperativos. Los tiempos verbales, el presente y el futuro. Las modalidades de los enunciados oscilan entre las epistémicas (sentencia, interrogación), existenciales (profecía) y factuales (plegaria). En relación con el cuerpo textual, todos los finales pueden aparecer integrados a la serie o a la estrofa final, o marcarse gráficamente constituyendo una estrofa en sí mismos. Por último, en lo que se refiere a la condición abierta o cerrada de los finales, la sentencia aparece como final cerrado porque implica un cumplimiento de las expectativas generadas y no suele dar lugar a ninguna apelación. Por el contrario, los otros 
tipos son abiertos. La interrogación a la vez que expresa una incertidumbre, deja abierto el eje temático desarrollado en el poema; la profecía, por su parte, enuncia una acción pendiente de resolución; por último, en la plegaria, el pedido al interlocutor invocado queda planteado, pero no se indica en el poema si éste cumplirá con el otorgamiento de lo solicitado.

Cabría preguntarse por el papel de estos tipos de finales en la percepción de la voz a través de sus marcas en la escritura. Si en la lírica, la voz de Olga Orozco es esencialmente ritual, la persistencia dominante de finales como la sentencia, la interrogación, la profecía y la plegaria, participan de una "puesta en escena" del rito: mediante el conjunto de sus estrategias compositivas, el texto sumerge al lector en ese ambiente y de allí la contundencia de sus efectos cognitivos y afectivos. Se trata de un rasgo muy evidente, por ejemplo, en "Para ser otra", "Para hacer un talismán" o "Para destruir a la enemiga" de Los juegos peligrosos, que adoptan la tipología de base procedimental. Pero también se puede reconocer por el uso estratégico, desde el punto de vista de la andadura rítmica y de la construcción global del poema, del paralelismo anafórico, tal como se ha podido observar en "No han cambiado y son otros" de La noche a la deriva. En síntesis, la configuración de la voz depende de la concurrencia de un conjunto de rasgos de estilo que han sido pensados con arte para provocar su reverberación y su encantamiento con cada actualización lectora.

\section{Referencias bibliográficas}

Agamben, Giorgio (2016), El final del poema, Buenos Aires, Adriana Hidalgo.

Alarcos Llorach, Emilio (1993), Gramática de la lengua española, Madrid, Espasa Calpe.

Apostel, Leo (1981), «De l'interrogation en tant qu'action», Langue Française, 52, págs. 23-43.

Austin, John L. (1990), Cómo hacer cosas con las palabras. Palabras y acciones, Barcelona, Paidós.

BAHTI, Timothy (1990) «End and Ending: On the Lyric Technique of Some Wallace Stevens Poems», Modern Language Notes, 105 (5), págs. 1046-1062 
Battiston, Dora, Bertón, Sonia, Salto, Graciela (Comps.) (2020), Los juegos de espejos: poética y subjetividad en Olga Orozco, Buenos Aires, Teseo/ Universidad Nacional de La Pampa.

- (2020). Médanos fugitivos: poética y archivo en Olga Orozco, Buenos Aires, Teseo/ Universidad Nacional de La Pampa.

BECCACECE, Hugo (1991) «Memorias de la oscuridad». Revista La Nación, Buenos Aires, $\mathrm{N}^{\circ} 1147,30$ de junio.

Bertucelli Papi, Marcélla (1996), ¿Qué es la Pragmática?, Barcelona, Paidós.

BRú, José (Comp.) (1998), Acercamientos a Olga Orozco: Premio Juan Rulfo 1998, Guadalajara, Universidad de Guadalajara.

CArroll, Lewis (1982), Alicia en el país de las maravillas, Trad. y prólogo de J. de Ojeda. $10^{a}$ ed. Madrid, Alianza.

Coвo Borda, Juan Gustavo (1984). «Poesía argentina: notas de lectura», en Juan G. Cobo Borda, María Julia De Ruschi Crespo, Ricardo H. Herrera, Usos de la imaginación, Buenos Aires, Ediciones de El Imaginero, págs. 5565.

Colombo, Stella Maris (1983), Metáfora y cosmovisión en la poesía de Olga Orozco, Rosario, Cuadernos Aletheia, Grupo de Estudios Semánticos.

COMBEtTes, Bernard (1977), «Ordre des éléments dans la phrase et linguistique du texte», Pratiques: linguistique, littérature, didactique, 13, págs. 91-101

COMBETTES, Bernard (1978), «Thématisation et progression thématique dans les récits d'enfants», Langue française, 38, págs. 74-86.

CRIAdo De VAl, Manuel (1992), La imagen del tiempo: verbo y relatividad, Madrid, Istmo.

De Beaugrande, Robert-Alain, Dressler, Wolfang Ulrich (1997), Introducción a la lingüística del texto, Barcelona, Ariel.

Dillon, Marta (1999), «LA OROZCO (GLORIAS) » Publicado en "Radar", Página 12, Accesible on line en: http:/ / www.pagina12.com.ar/diario/verano12/23-79414-2007-01-23.html 
FABB, Nigel (2016), «Proccesing Effort an Poetic Closure», International Journal of Literary Linguistics, 5(4), págs. 1-22.

FLoREs, Félix Gabriel (1996), Poetas argentinos contemporáneos, Buenos Aires, Editorial Vinciguerra.

Gadamer, Hans Georg (1984), Verdad y método, Madrid, Ediciones Sígueme.

Hartman, Geoffrey H. (1975), Beyond Formalism. Literary Essays 1958-1970, New Haven/ London, Yale University Press.

Heller-Roazen, Daniel (2003), «Des Altérités de la langue. Plurilinguismes poétiques au Moyen Âge», Littérature, 130, págs. 75-96

Herrnstein Smith, Barbara (1968), Poetic Closure. A Study of How Poems End, Chicago, University of Chicago Press.

LAUSBERG, Heinrich (1975), Elementos de retórica literaria. Introducción al estudio de la filología clásica, románica, inglesa y alemana, Madrid, Gredos.

Legaz, María Elena (2010), La escritura poética de Olga Orozco. Una lección de luz, Buenos Aires, Corregidor.

Lergo Martín, Inmaculada (Coord.) (2010), Olga Orozco. Territorios de fuego para una poética. Sevilla, Secretariado de Publicaciones de la Universidad de Sevilla.

LisCANo, Juan (1975), «Olga Orozco y su trascendente juego poético». Prólogo a: Olga Orozco, Veintinueve poemas, Caracas, Monte Ávila, págs. 9-35.

Lojo, María Rosa (1988), «En el revés del cielo, por Olga Orozco», La Nación, Buenos Aires, domingo 24 de enero, Suplemento "Cultura”, pág. 3.

LÓPEZ DE EsPINOZA, Susana Beatriz (1987), «Retórica de la máscara y el rostro en la poesía de Olga Orozco», Estudios de Literatura Argentina II, 8, Sección Crítica, Segunda Serie, págs. 37-45.

Luján Atienza, Ángel L. (1999), Cómo se comenta un poema, Madrid, Síntesis.

Luzzani Bystrowicz, Telma (1981), «Olga Orozco: poesía de la totalidad», Capitulo; la historia de la literatura argentina, Buenos Aires, CEAL, págs. 227-231. 
MeYer, Michel (1993), Questions de rhétorique. Langage, raison et séduction, Paris, Le Livre de Poche.

Molinié, Georges (1992), Dictionnaire de rhétorique, Paris, Le Livre de Poche.

MonteleOne, Jorge (2020), "La voz de Olga: representaciones subjetivas en la obra de Olga Orozco", en Battiston, Dora, Bertón, Sonia, Salto, Graciela (eds.). Los juegos de espejos..., págs. 15-38.

Mujica, Hugo (1988), «Olga Orozco. En el revés del cielo», Revista Iberoamericana, LIV (144-145), págs. 1084-1089.

Orozco, Olga (1946), Desde lejos, Buenos Aires, Losada.

- (1962), Los juegos peligrosos, Buenos Aires, Losada.

- (1977), Cantos a Berenice, Buenos Aires, Editorial Sudamericana.

- (1983), La noche a la deriva, México, FCE.

- (1987), En el revés del cielo, Buenos Aires, Editorial Sudamericana.

- (2012), Poesía completa, Buenos Aires, Adriana Hidalgo.

- "Conferencia dictada en la Universidad de La Pampa", Texto inédito mecanografiado, cedido por la escritora (sin mención de fecha).

Pellarolo, Silvia (1989), «La imagen de la estatua de sal: síntesis y clave en el pensamiento poético de Olga Orozco», Mester XVIII(1), págs. 41-49.

PIÑA, Cristina (1984), «Estudio preliminar» a Olga Orozco. Páginas de Olga Orozco seleccionadas por la autora, Buenos Aires, Celtia, págs. 13-54.

PIÑA, Cristina (1994), «Olga Orozco. La poesía es un animal salvaje oculto en la maleza», First, Buenos Aires, Enero, págs. 94-97.

Pottier, Bernard (1992), Teoría y análisis en lingüística, Madrid, Gredos.

RunNing, Thorpe (1987). «Imagen y creación en la poesía de Olga Orozco», Letras Femeninas, 13(1/2), 12-20. doi:10.2307/23022396

SAUTER, Silvia (2006), Teoría y práctica del proceso creativo. Con entrevistas a Ernesto Sábato, Ana María Fagundo, Olga Orozco, María Rosa Lojo, Raúl Zurita y José Watanabe, Madrid/ Frankfurt am Main, Iberoamericana/ Vervuert. 
Sicre, José Luis (1992) Profetismo en Israel, Pamplona, Verbo Divino.

SIFrin, Mónica (1994), «Olga Orozco. De ausencias y de pérdidas», Clarín, Buenos Aires, jueves 5 de mayo, Suplemento "Cultura y Nación”, págs. 6-7.

SPANG, Kurt (1984), Fundamentos de retórica, Pamplona, EUNSA.

Steiner, George (1980), Después de Babel. Aspectos del lenguaje y la traducción, México, FCE.

TACCONI, María del Carmen (1981), «Para una lectura simbólica de Olga Orozco», Sur, Buenos Aires, 348, págs. 116-123.

TAmine-Gardes, Joëlle (1985), «Sur quelques procédés de style dans À la mystérieuse de Robert Desnos», L'Information Grammaticale, 25, págs. 32-35.

ZonANA, Víctor Gustavo (2003) «Imágenes de la memoria en la obra de Olga Orozco», en Boletín de la Academia Argentina de Letras, LXVII, 265-266, págs. 327-345.

- (2010), «Hacia la definición de los rasgos de estilo. El desarrollo expresivo de Olga Orozco entre 1938 y 1946», en Inmaculada Lergo Martín (Coord.), Olga Orozco. Territorios de fuego..., págs. 129-146. 